\title{
An Autosomal Genomic Scan for Loci Linked to Prediabetic Phenotypes in Pima Indians
}

\author{
Richard E. Pratley, ${ }^{\star}$ D. Bruce Thompson, ${ }^{\star}$ Michal Prochazka, ${ }^{\star}$ Leslie Baier, ${ }^{\star}$ David Mott, ${ }^{\star}$ Eric Ravussin, ${ }^{\star}$ Hakan Sakul, ${ }^{\ddagger}$ \\ Margaret G. Ehm, ${ }^{\S}$ Daniel K. Burns, ${ }^{\S}$ Tatiana Foroud, $\|$ W. Timothy Garvey, ${ }^{\pi}$ Robert L. Hanson, ${ }^{\star}$ William C. Knowler, ${ }^{\star}$ \\ Peter H. Bennett, ${ }^{*}$ and Clifton Bogardus* \\ *Phoenix Epidemiology and Clinical Research Branch, National Institute of Diabetes and Digestive and Kidney Diseases, National \\ Institutes of Health, Phoenix, Arizona 85016; ${ }^{\ddagger}$ Department of Statistical Genetics, Sequana Therapeutics, Inc., La Jolla, California 92037; \\ ${ }^{\S}$ Glaxo Wellcome, Inc., Research Triangle Park, North Carolina 27709; "Department of Medical Genetics, Indiana University School of \\ Medicine, Indianapolis, Indiana 46202; and "Department of Medicine, Medical University of South Carolina, Ralph H. Johnson Veterans \\ Affairs Medical Center, Charleston, South Carolina 29425
}

\begin{abstract}
Type 2 diabetes mellitus is a common chronic disease that is thought to have a substantial genetic basis. Identification of the genes responsible has been hampered by the complex nature of the syndrome. Abnormalities in insulin secretion and insulin action predict the development of type 2 diabetes and are, themselves, highly heritable traits. Since fewer genes may contribute to these precursors of type 2 diabetes than to the overall syndrome, such genes may be easier to identify. We, therefore, undertook an autosomal genomic scan to identify loci linked to prediabetic traits in Pima Indians, a population with a high prevalence of type 2 diabetes.
\end{abstract}

363 nondiabetic Pima Indians were genotyped at 516 polymorphic microsatellite markers on all 22 autosomes. Linkage analyses were performed using three methods (single-marker, nonparametric multipoint [MAPMAKER/SIBS], and variance components multipoint). These analyses provided evidence for linkage at several chromosomal regions, including 3q21-24 linked to fasting plasma insulin concentration and in vivo insulin action, $4 \mathrm{p} 15-\mathrm{q} 12$ linked to fasting plasma insulin concentration, 9q21 linked to 2-h insulin concentration during oral glucose tolerance testing, and 22q1213 linked to fasting plasma glucose concentration. These results suggest loci that may harbor genes contributing to type 2 diabetes in Pima Indians. None of the linkages exceeded a LOD score of 3.6 (a 5\% probability of occurring in a genome-wide scan). These findings must, therefore, be considered tentative until extended in this population or replicated in others. (J. Clin. Invest. 1998. 101:1757-1764.) Key words: type 2 diabetes mellitus $\cdot$ glucose tolerance $\bullet$ insulin secretion $\bullet$ insulin action $\cdot$ genetics

Portions of this work have appeared in abstract form (1997. Diabetologia. 40[Suppl. 1]; 158a) and (1997. Diabetes. 46[Suppl. 1]; 170a).

Address correspondence to Richard E. Pratley, Clinical Diabetes and Nutrition Section, NIDDK/NIH, 4212 North 16th Street, Phoenix, AZ 85016. Phone: 602-200-5312; FAX: 602-200-5335; E-mail: Richard_Pratley@nih.gov

Received for publication 26 September 1997 and accepted in revised form 18 February 1998.

The Journal of Clinical Investigation

Volume 101, Number 8, April 1998, 1757-1764

http://www.jci.org

\section{Introduction}

Diabetes mellitus is a common chronic disease, afflicting an estimated 16 million persons in the United States (1). Most affected individuals ( $>90 \%$ ) have type 2 or non-insulin-dependent diabetes mellitus (NIDDM) ${ }^{1}$ and the majority of these manifest a common phenotype which includes obesity, insulin resistance, impaired insulin secretion, and increased rates of endogenous glucose production (2).

Substantial evidence indicates that susceptibility to type 2 diabetes is largely genetically determined (3). A relatively rare form of diabetes, maturity onset diabetes of the young (MODY), characterized by an early onset and transmitted as an autosomal dominant has been associated with mutations in at least 3 different genes; glucokinase $(G C K)$, hepatic nuclear factor 1- $\alpha(T C F 1)$, and hepatic nuclear factor 4- $\alpha$ (TCF14) (4-6). Another rare form of diabetes characterized by maternal transmission and deafness has been associated with mutations in mitochondrial DNA (7). Most cases of type 2 diabetes do not follow a simple Mendelian pattern of transmission, however. Multiple genes with small to moderate effects may to contribute to individual susceptibility in these cases. This complex pattern of inheritance confounds the identification of genes contributing to common forms of type 2 diabetes.

Studies of the genetics of type 2 diabetes may be facilitated if genetic and phenotypic heterogeneity can be limited by carefully selecting relatively homogenous populations and studying metabolic traits that are precursors of diabetes $(8,9)$. Type 2 diabetes is much more common in the Pima Indians of Arizona than in the general U.S. population (10). Among the Pima Indians, diabetes developing before age 45 increases the risk of diabetes to the offspring two to fourfold (11) and segregation analyses are consistent with the presence of a major gene affecting age of onset of diabetes (12). Obesity, higher fasting and 2-h glucose and insulin concentrations during an

1. Abbreviations used in this paper: 2-hour glucose, 2-h plasma glucose concentration during the oral glucose tolerance test; 2-hour insulin, 2-h plasma insulin concentration during the oral glucose tolerance test; AIR, acute insulin response (3-5 min) above basal during the intravenous glucose tolerance test; IVGTT 10' insulin, $10 \mathrm{~min}$ plasma insulin response above basal during the intravenous glucose tolerance test; OGTT 30' insulin, 30 min plasma insulin concentration during the oral glucose tolerance test; $\mathrm{M}_{\text {low }}$, glucose disposal during the low $\left(40 \mathrm{mU} / \mathrm{m}^{2}\right.$ per $\mathrm{min}$ ) insulin infusion of the glucose clamp; $\mathrm{M}_{\mathrm{high}}$, glucose disposal during the high $\left(400 \mathrm{mU} / \mathrm{m}^{2}\right.$ per $\left.\mathrm{min}\right)$ insulin infusion of the glucose clamp; MODY, maturity onset diabetes of the young; NIDDM, non-insulin-dependent diabetes mellitus. 
oral glucose tolerance test, insulin resistance, and impaired insulin secretion predict the development of type 2 diabetes (11, 13) and are themselves highly heritable traits in Pima Indians (14). The genes influencing each of these metabolic precursors of type 2 diabetes are likely to be fewer in number and, therefore, may be easier to identify than those contributing to the overall syndrome. Consequently, we undertook an autosomal genomic scan to identify loci linked to measures of glucose tolerance, insulin secretion, and insulin action in Pima Indians.

\section{Methods}

Subjects. 363 nondiabetic Pima Indians (221 male/142 female) who participated in a prospective study of the predictors of type 2 diabetes between 1983 and 1996 (13) and who had at least one full sibling who also participated in the studies were selected for the present analyses. Since even mild impairment in glucose tolerance is associated with a secondary impairment in insulin secretion, a subset of 231 individuals with fasting and 2-h plasma glucose concentrations $<7.8 \mathrm{mM}$ during a 75-gram oral glucose tolerance test (15) was identified for analyses related to insulin secretion. Table I summarizes the distribution of sibling-pairs (sib-pairs) among the families in the entire group and the subgroup with normal glucose tolerance. This study was approved by the Institutional Review Board of the National Institute of Diabetes and Digestive and Kidney Diseases (NIDDK) and the Tribal Council of the Gila River Indian Community, and all subjects gave written informed consent before participation.

Metabolic testing. The methods used to characterize subjects have been described in detail elsewhere (13). Briefly, subjects were admitted to the Clinical Research Center for 10-12 days and were provided a weight-maintaining diet containing $50 \%$ of calories as carbohydrate, $30 \%$ as fat, and $20 \%$ as protein. Percent body fat and fatfree mass were determined by hydrodensitometry and the pattern of body fat distribution was indexed as the waist/thigh circumference ratio. After at least $3 \mathrm{~d}$ on the metabolic diet, a 75-gram oral glucose tolerance test (OGTT) was performed. On a subsequent day, insulin responses to an intravenous glucose challenge (IVGTT) were measured in plasma samples obtained 3, 4, 5, 6, 8, and $10 \mathrm{~min}$ after the injection of 25 gram of glucose. The acute insulin response (AIR) was defined as the mean increment in plasma insulin concentration above basal 3-5 min after the injection of glucose. As additional indices of the acute insulin response, the 10-min insulin concentration during the IVGTT and the 30-min insulin concentration during the OGTT were analyzed. The former measure was chosen based on analyses which indicate that this time point is the most highly heritable index of insulin secretion among the Pima Indians (14). The latter index of insulin secretion has recently been demonstrated to distinguish Finnish families in which type 2 diabetes is linked to markers near the

\section{Table I. Distribution of Families}

\begin{tabular}{lrr}
\hline & Total group & Normal glucose tolerance group \\
\hline Individuals & 363 & 231 \\
Nuclear families & 109 & 71 \\
Families with: & & \\
1 sib-pair & 58 & 43 \\
3 sib-pairs & 28 & 20 \\
6 sib-pairs & 13 & 5 \\
10 sib-pairs & 3 & 1 \\
15 sib-pairs & 4 & 1 \\
21 sib-pairs & 2 & 1 \\
36 sib-pairs & 1 & 186 \\
Total no. of sib-pairs & 388 & \\
& & \\
\hline
\end{tabular}

Table II. Subject Characteristics

\begin{tabular}{lcc}
\hline & Total group & $\begin{array}{c}\text { Normal glucose } \\
\text { tolerance group }\end{array}$ \\
\hline Sex (M/F) & $221 \mathrm{M} / 142 \mathrm{~F}$ & $152 \mathrm{M} / 79 \mathrm{~F}$ \\
Age (yr) & $26.7 \pm 0.3$ & $25.9 \pm 0.4$ \\
Height $(\mathrm{cm})$ & $166.6 \pm 0.4$ & $166.9 \pm 0.5$ \\
Weight $(\mathrm{kg})$ & $92.4 \pm 1.2$ & $90.5 \pm 1.5$ \\
Body fat $(\%)$ & $31.9 \pm 0.4$ & $30.8 \pm 0.6$ \\
Waist/thigh ratio & $1.63 \pm 0.01$ & $1.61 \pm 0.01$ \\
Fasting glucose (mmol/liter) & $5.0 \pm 0.1$ & $4.9 \pm 0.1$ \\
2-h glucose (mmol/liter) & $6.9 \pm 0.1$ & $6.4 \pm 0.1$ \\
Fasting insulin (pmol/liter) & $235 \pm 5$ & $215 \pm 5$ \\
2-h insulin (pmol/liter) & $1080 \pm 50$ & $895 \pm 55$ \\
AIR (pmol/liter) & & $1280 \pm 65$ \\
IVGTT 10' insulin (pmol/liter) & & $1000 \pm 50$ \\
OGTT 30' insulin (pmol/liter) & & $1355 \pm 60$ \\
$\mathrm{M}_{\text {low }}\left(\mu \mathrm{mol} / \mathrm{kg}_{\text {embs }}\right.$ per min) & $16.2 \pm 0.3$ & \\
$\mathrm{M}_{\text {high }}\left(\mu \mathrm{mol} / \mathrm{kg}_{\text {embs }}\right.$ per min) & $48.7 \pm 0.6$ & \\
\hline
\end{tabular}

Values are mean \pm SE. Measures of the acute insulin response were only analyzed in subjects with normal glucose tolerance.

TCF1 locus on chromosome 12 (16). 7-10 d after admission, glucose disposal, an index of in vivo insulin action, was measured at physiologic $\left(\mathrm{M}_{\text {low }}\right)$ and maximally stimulating $\left(\mathrm{M}_{\text {high }}\right)$ insulin concentrations (steady state plasma insulin concentrations $845 \pm 10$ and $12,210 \pm 185$ $\mathrm{pmol} /$ liter, respectively, mean $\pm \mathrm{SE}$ ) using a two-step hyperinsulinemic-euglycemic glucose clamp protocol. Glucose disposal rates were corrected for endogenous glucose production $\left(\mathrm{M}_{\text {low }}\right.$ only) and expressed per kilogram estimated metabolic body size $(\mathrm{EMBS}=\mathrm{fat}$ free mass + 17.7) (17). Fasting glucose and insulin concentrations were determined on at least three separate days during the period of metabolic testing and the means of these measurements were used in subsequent analyses. Many of the subjects were evaluated on more than one occasion in the course of the longitudinal study, but only data from their initial visit are included in the present analyses. The physical and metabolic characteristics of the subjects are summarized in Table II.

Genotyping. Subjects were genotyped at 516 polymorphic microsatellite markers distributed on all 22 autosomes. The majority of genotypes were determined by the Marshfield Medical Research Foundation using fluorescent or radioactive-labeled primers $(18,19)$. Additional markers near specific candidate genes or within scan gaps were genotyped at Glaxo Wellcome, Inc. (Research Triangle Park, NC). The median heterozygosity of these markers in Pima Indians was 0.68 , and the median distance between markers was $6.4 \mathrm{cM}$ (range 0-25.6). Marker data were checked for pedigree and typing errors (20). A genetic map specific for the Pima Indians was constructed using CRI-MAP (21). The multipoint information content (the inheritance information extracted by the markers used in the genomic scan) based on this map was $>0.5$ for $97 \%$ of the genome and $>0.6$ for $84 \%$ of the genome.

Statistical analyses. Descriptive statistical analyses were performed using the procedures of the SAS Institute (Cary, NC). Fasting insulin concentrations, insulin responses to the OGTT and IVGTT and glucose disposal during the low dose of the clamp were $\log _{10}$ transformed to approximate a normal distribution before analyses. To control for the effects of age, sex, percent body fat, and body fat distribution, multiple linear regression analyses were used to adjust all metabolic variables for these factors prior to linkage analyses. Measures of insulin secretion (AIR, 10-min insulin during the IVGTT and $30 \mathrm{~min}$ insulin during the OGTT) were further adjusted for $\mathrm{M}_{\text {low }}$ since these phenotypes also vary as a function of insulin sensitivity. 
Allele frequencies were estimated from $\sim 1330$ Pima Indians genotyped for a larger study of the genetics of diabetes (22) from which the present subset of subjects was drawn. Genotyping data for one parent was available in $\sim 30 \%$ of subjects, whereas data on both parents was available in only a small minority of individuals. The proportion of alleles identical by descent was estimated and single-marker nonparametric sib-pair linkage analyses were performed using the SIBPAL procedure of the Statistical Analysis for Genetic Epidemiology package (S.A.G.E. 2.2, 1994). Multipoint analyses were performed using the MAPMAKER/SIBS program (23) to directly estimate the proportion of alleles identical by descent and the Haseman-Elston regression (24) to assess linkage. $P$ values were calculated from a $t$ distribution with a modified number of degrees of freedom (25) to adjust for the nonindependence of sib-pairs in these analyses and converted into equivalent LOD scores assuming a onetailed test and a chi-square distribution (26). Multipoint linkage analyses were also performed using a variance components method (27). This method uses a linear mixed model in which the overall trait mean $(\mu)$ is estimated as a fixed effect and the variance in the trait is partitioned into three random effects: a monogenic component linked to the region of interest $\left(\sigma_{\mathrm{M}}^{2}\right)$, a polygenic component representing overall familial effects $\left(\sigma_{\mathrm{G}}{ }^{2}\right)$ and an environmental component incorporating effects unique to each individual $\left(\sigma_{\mathrm{E}}^{2}\right)$. The parameters of these models are estimated by maximizing the likelihood over all sibships using the scoring algorithm (28), under the assumption that the trait is normally distributed. The null hypothesis of no linkage was compared to one in which $\sigma_{\mathrm{M}}^{2}$ was constrained to equal 0 . These analyses also used the MAPMAKER/SIBS algorithm to estimate the proportion of alleles identical by descent. Linkage analyses used all possible sib-pairs, but were not extended to other degrees of relationships. Analyses with measures of glucose tolerance and insulin action were performed in the entire group of nondiabetic subjects, whereas those with measures of insulin secretion were restricted to individuals with normal glucose tolerance. All LOD scores $\geq 0.2$ (corresponding to $P<0.01)$ in single-marker and multipoint nonparametric and vari- ance components linkage analyses are reported. In a complete genome scan $\sim 5$ loci per phenotype tested would be expected to exceed of LOD of 1.2 by chance, alone (29). However, no attempt was made to adjust for multiple trait testing in these exploratory analyses. Complete results of the linkage analyses are available from the corresponding author.

\section{Results}

43 loci showed evidence of linkage (LOD scores $\geq 1.2$ ) to fasting or 2-h glucose or insulin concentrations in either singlemarker, multipoint or variance components linkage analyses (Tables III and IV). 19 loci showed evidence of linkage to measures of insulin secretion (Table V) and 12 loci showed evidence of linkage to insulin action (Table VI). Among the loci with LOD scores $\geq 1.2$, eight regions of interest were identified based on the strength of the linkage result, correspondence of linkage results among multiple methods of analysis, or concordance among closely related phenotypes.

A region on $3 \mathrm{q} 21-24$ containing the marker D3S1764 showed evidence for linkage to fasting insulin concentrations (multipoint LOD scores of 1.72 and 1.49 with MAPMAKER/ SIBS and variance components method, respectively; Table IV) and insulin action $\left(\mathrm{M}_{\text {low }}\right)$ at physiologic insulin concentrations (multipoint LOD scores of 2.48 and 1.13, respectively; Table VI) (Fig. 1). D3S1764 also showed some evidence $(\mathrm{LOD}=1.50$; Table VI) for linkage with insulin action at maximally stimulating insulin concentrations $\left(\mathrm{M}_{\text {high }}\right)$ and a nearby marker, D3S1744, located $7.9 \mathrm{cM}$ telomeric from D3S1764, showed evidence of linkage $(\mathrm{LOD}=2.31$; Table IV) to the $2-\mathrm{h}$ insulin concentration. On 4p15-q12 five markers (D4S2629D4S2382-D4S1627-D4S3242-D4S3248) spanning $\sim 20 \mathrm{cM}$

Table III. Markers Linked (LOD $\geq 1.2)$ to Adjusted Fasting and 2-h Glucose Concentrations

\begin{tabular}{|c|c|c|c|c|c|c|c|c|}
\hline & \multirow[b]{2}{*}{ Chromosome } & \multirow[b]{2}{*}{ Marker name } & \multirow[b]{2}{*}{ Single marker LOD } & \multirow[b]{2}{*}{$\mathrm{cM}$} & \multicolumn{4}{|c|}{ Multipoint LOD } \\
\hline & & & & & MAPMAKER/SIBS & $\mathrm{cM}$ & Variance components & $\mathrm{cM}$ \\
\hline \multicolumn{9}{|l|}{ Fasting glucose } \\
\hline & 1 & D1S1663 & 1.54 & 217.9 & 0.39 & 218 & 0.09 & 218 \\
\hline & 2 & D2S1329 & 0.09 & 0 & 1.00 & 14 & 1.40 & 0 \\
\hline & 4 & D4S3248 & 1.45 & 77.6 & 0.13 & 77 & 0.37 & 79 \\
\hline & 4 & D4S3243 & 1.87 & 94.3 & 1.30 & 101 & 0.57 & 95 \\
\hline & 6 & D6S273 & 1.04 & 41.4 & 0.90 & 41 & 1.79 & 41 \\
\hline & 7 & D7S559 & 0.49 & 191.4 & 0.49 & 191 & 1.23 & 192 \\
\hline & 8 & D8S1469 & 0.57 & 10.4 & 1.43 & 8 & 1.72 & 10 \\
\hline & 22 & D22S683 & 1.35 & 36.1 & 3.15 & 43 & 1.31 & 36 \\
\hline & 22 & $\mathrm{D} 22 \mathrm{~S} 270$ & 1.75 & 45.6 & 2.99 & 46 & 2.39 & 46 \\
\hline \multicolumn{9}{|l|}{ 2-h glucose } \\
\hline & 1 & D1S1595 & 1.34 & 153.4 & 0.28 & 154 & 0.52 & 153 \\
\hline & 2 & D2S5131 & 1.49 & 14.7 & 0.67 & 15 & 0.24 & 15 \\
\hline & 4 & GATA62A11 & 1.85 & 103.2 & 1.78 & 103 & 0.79 & 103 \\
\hline & 7 & D7S1802 & 1.26 & 31.5 & 0.77 & 31 & 0.82 & 32 \\
\hline & 9 & D9S925 & 1.37 & 24.0 & 0.90 & 24 & 0.26 & 31 \\
\hline & 9 & D9S2026 & 1.25 & 107.4 & 0.00 & 107 & 0.08 & 107 \\
\hline & 10 & D10S1237 & 1.25 & 139.4 & 1.21 & 143 & 0.66 & 149 \\
\hline & 16 & D16S2621 & 0.70 & 125.6 & 1.23 & 124 & 1.12 & 126 \\
\hline & 19 & D19S589 & 0.57 & 75.2 & 1.25 & 76 & 1.14 & 75 \\
\hline
\end{tabular}

All variables were adjusted for age, sex, percent fat, and waist/thigh ratio. 


\begin{tabular}{|c|c|c|c|c|c|c|c|c|}
\hline & \multirow[b]{2}{*}{ Chromosome } & \multirow[b]{2}{*}{ Marker name } & \multirow[b]{2}{*}{ Single marker LOD } & \multirow[b]{2}{*}{$\mathrm{cM}$} & \multicolumn{4}{|c|}{ Multipoint LOD } \\
\hline & & & & & MAPMAKER/SIBS & $\mathrm{cM}$ & Variance Components & $\mathrm{cM}$ \\
\hline \multicolumn{9}{|l|}{ Fasting insulin } \\
\hline & 3 & D3S2403 & 0.03 & 32.0 & 1.12 & 32 & 1.30 & 35 \\
\hline & 3 & D3S3038 & 1.59 & 42.2 & 1.35 & 40 & 1.25 & 45 \\
\hline & 3 & D3S1764 & 1.48 & 149.9 & 1.72 & 150 & 1.49 & 150 \\
\hline & 3 & D3S2427 & 1.14 & 188.4 & 0.91 & 188 & 1.22 & 188 \\
\hline & 4 & D4S2629 & 1.99 & 53 & 0.64 & 53 & 0.29 & 53 \\
\hline & 4 & D4S2382 & 2.75 & 58.3 & 1.15 & 59 & 0.89 & 61 \\
\hline & 4 & D4S1627 & 2.02 & 66 & 0.68 & 66 & 0.98 & 67 \\
\hline & 4 & D4S3242 & 1.34 & 68 & 1.09 & 72 & 1.15 & 68 \\
\hline & 4 & D4S3248 & 0.60 & 77.6 & 0.84 & 77 & 1.50 & 74 \\
\hline & 9 & D9S1123 & 1.64 & 63.1 & 1.44 & 68 & 0.66 & 63 \\
\hline & 9 & D9S1120 & 0.37 & 76.1 & 0.49 & 76 & 1.42 & 70 \\
\hline & 11 & D11S1396 & 1.52 & 92.2 & 0.25 & 92 & 0.09 & 92 \\
\hline & 19 & D19S714 & 0.63 & 20.5 & 0.30 & 20 & 1.33 & 18 \\
\hline \multicolumn{9}{|l|}{ 2-h insulin } \\
\hline & 3 & D3S1744 & 2.31 & 157.8 & 1.38 & 160 & 1.07 & 160 \\
\hline & 3 & D3S3053 & 1.37 & 181.1 & 0.34 & 179 & 0.42 & 181 \\
\hline & 7 & D7S3061 & 2.56 & 131.7 & 1.78 & 131 & 0.86 & 131 \\
\hline & 9 & D9S168 & 1.01 & 10.0 & 1.84 & 17 & 0.48 & 20 \\
\hline & 9 & D9S903 & 1.22 & 69.3 & 0.83 & 69 & 1.46 & 69 \\
\hline & 9 & D9S910 & 1.63 & 95.5 & 1.53 & 96 & 2.03 & 96 \\
\hline & 9 & D9S938 & 0.45 & 98.8 & 1.94 & 99 & 2.16 & 98 \\
\hline & 11 & D11S1975 & 1.61 & 79.0 & 0.99 & 79 & 0.38 & 79 \\
\hline & 11 & D11S2371 & 2.04 & 82.6 & 1.31 & 83 & 0.46 & 82 \\
\hline & 11 & D11S1396 & 1.52 & 92.2 & 0.54 & 92 & 0.22 & 93 \\
\hline & 11 & D11S2000 & 1.23 & 108.7 & 0.93 & 108 & 0.80 & 109 \\
\hline & 12 & D12S1052 & 1.32 & 80.7 & 0.15 & 85 & 0.27 & 89 \\
\hline & 15 & gata50c03 & 0.71 & 30.7 & 0.59 & 31 & 1.50 & 31 \\
\hline & 16 & D16S2613 & 1.52 & 19.7 & 0.13 & 20 & 0.70 & 20 \\
\hline & 16 & D16S2621 & 1.29 & 125.6 & 1.33 & 126 & 0.52 & 126 \\
\hline
\end{tabular}

All variables were adjusted for age, sex, percent fat, and waist/thigh ratio.

showed evidence of linkage to fasting plasma insulin concentration (single marker LOD scores 0.6-2.75, maximal multipoint LOD $=1.15$ at $59 \mathrm{cM}$ with MAPMAKER/SIBS and 1.50 at $74 \mathrm{cM}$ in variance components analyses; Table IV) and a fifth marker in this region, D4S3255, showed evidence of linkage to $\mathrm{M}_{\text {high }}$ (single marker LOD $=2.63$; Table VI). Three markers on 8p22-23 (D8S1132-GATA101F101-D8S592) which span $\sim 9 \mathrm{cM}$ showed evidence of linkage to two measures of acute insulin secretion; the 10-min insulin concentration during the IVGTT (multipoint LOD $=1.27$ in variance components analyses; Table V) and the 30-min insulin concentration during the OGTT (multipoint LOD $=1.48$ using MAPMAKER/ SIBS; Table V).

On 9q21, a region containing D9S903 (69.3 cM) and D9S1120 (76.1 cM) showed evidence of linkage to fasting and 2-h OGTT insulin concentration (multipoint LOD $\sim 1.42$ with both methods; Table IV) (Fig. 2). A second peak on chromosome 9 in the region flanked by $D 9 S 910(95.5 \mathrm{cM})$ and $D 9 S 938$ (98.8 cM) showed even greater evidence of linkage to 2-h OGTT insulin concentration (multipoint LOD = 1.94 and 2.16 with MAPMAKER/SIBS and variance components methods; Table IV). A broad ( $~ 30 \mathrm{cM})$ region of interest, flanked by $D 11 S 1975(79 \mathrm{cM})$ and $D 11 S 2000(108.7 \mathrm{cM})$ on $11 \mathrm{q} 13$, contained four markers (D11S1975-D11S2371-D11S1396D11S2000) with evidence of linkage to the 2-h insulin during the OGTT (single marker LOD = 1.23-2.04, multipoint LOD 1.31 using MAPMAKER/SIBS; Table IV). A fifth marker in this region, D11S1396, also showed evidence of linkage to fasting plasma insulin concentration (single marker LOD $=1.52$; Table IV). Chromosome 12 contained a region flanked by D12S1052 (80.7 cM) and D12S1297 (89 cM) with evidence of linkage to 2-h OGTT insulin concentration (single marker LOD $=1.32$; Table IV) and $\mathrm{M}_{\text {high }}$ (multipoint LOD scores = 2.05 and 1.20 in MAPMAKER/SIBS and variance components analyses; Table IV).

Two regions of interest were identified on chromosome 22. The p-terminal end contained a locus (D22S420) with evidence for linkage to $\mathrm{M}_{\text {high }}$ (multipoint $\mathrm{LOD}=1.90$ and 2.12 using MAPMAKER/SIBS and variance components methods; Table VI \& Fig. 3) while 22q12-13 contained two markers, $D 22 S 683$ at $36.1 \mathrm{cM}$ and $D 22 S 270$ at $45.6 \mathrm{cM}$, showing evidence of linkage to fasting glucose concentration (Fig. 3). These latter loci provided the strongest evidence of linkage to a prediabetic phenotype obtained in this genome scan (multi- 


\begin{tabular}{|c|c|c|c|c|c|c|c|c|}
\hline & \multirow[b]{2}{*}{ Chromosome } & \multirow[b]{2}{*}{ Marker name } & \multirow[b]{2}{*}{ Single marker LOD } & \multirow[b]{2}{*}{$\mathrm{cM}$} & \multicolumn{4}{|c|}{ Multipoint LOD } \\
\hline & & & & & MAPMAKER/SIBS & $\mathrm{cM}$ & Variance components & $\mathrm{cM}$ \\
\hline \multicolumn{9}{|l|}{ AIR } \\
\hline & 3 & D3S2406 & 0.44 & 97.0 & 0.34 & 96 & 1.24 & 94 \\
\hline & 4 & D4S415 & 1.08 & 192.6 & 1.05 & 193 & 1.57 & 193 \\
\hline & 5 & D5S820 & 1.41 & 170.8 & 0.70 & 165 & 0.35 & 172 \\
\hline & 7 & D7S2201 & 1.81 & 4.4 & 0.00 & 4 & 0.09 & 4 \\
\hline & 7 & D7S798 & 0.62 & 180.4 & 1.49 & 183 & 0.28 & 181 \\
\hline \multicolumn{9}{|l|}{ IVGTT $10^{\prime}$ insulin } \\
\hline & 3 & D3S3026 & 1.57 & 66.8 & 0.92 & 67 & 0.71 & 67 \\
\hline & 3 & D3S3054 & 1.24 & 214.2 & 0.64 & 214 & 0.91 & 214 \\
\hline & 5 & D5S2505 & 1.65 & 16.7 & 0.97 & 17 & 0.76 & 17 \\
\hline & 7 & D7S559 & 1.79 & 191.4 & 1.78 & 190 & 0.75 & 189 \\
\hline & 8 & D8S1132 & 0.74 & 111.8 & 0.73 & 112 & 1.27 & 112 \\
\hline & 8 & GATA101F01 & 1.62 & 115.3 & 0.81 & 115 & 1.11 & 116 \\
\hline & 15 & D15S659 & 1.32 & 40.4 & 1.46 & 45 & 0.42 & 49 \\
\hline & 18 & D18S64 & 1.12 & 85.5 & 1.42 & 86 & 0.75 & 94 \\
\hline \multicolumn{9}{|l|}{ OGTT $30^{\prime}$ insulin } \\
\hline & 1 & D1S1589 & 1.53 & 181.4 & 0.15 & 181 & 0.18 & 181 \\
\hline & 1 & D1S235 & 1.33 & 252.3 & 1.41 & 258 & 0.72 & 253 \\
\hline & 3 & D3S3039 & 1.20 & 98.2 & 1.27 & 98 & 0.21 & 98 \\
\hline & 8 & D8S592 & 0.26 & 120.2 & 1.48 & 120 & 0.86 & 120 \\
\hline & 12 & D12S1294 & 1.47 & 72.7 & 0.89 & 74 & 0.39 & 75 \\
\hline & 14 & D14S748 & 1.15 & 38.6 & 1.87 & 39 & 0.94 & 40 \\
\hline
\end{tabular}

All variables were analyzed in subjects with normal glucose tolerance and were adjusted for age, sex, percent fat, waist/thigh ratio, and $\mathrm{M}_{\mathrm{low}}$.

point LOD scores $=3.15$ and 2.39 in MAPMAKER/SIBS and variance components analyses, respectively; Table III).

\section{Discussion}

To identify potential genetic determinants of type 2 diabetes, we performed an autosomal genomic scan to search for evidence of linkage to prediabetic metabolic phenotypes in 363 well characterized nondiabetic Pima Indians from 109 nuclear families. These analyses identified several regions with evidence of linkage to aspects of glucose metabolism which predict type 2 diabetes in Pima Indians.

On chromosome 3 , the linkage to fasting plasma insulin concentration and insulin action at physiologic insulin concentrations at D3S1764 maps to 3q21-24. The structural gene for glycogenin $(G Y G)$ is a potential candidate gene located in this region. Glycogenin initiates glycogen formation (30), the main pathway of glucose disposal (and therefore insulin action) during the hyperinsulinemic glucose clamp (2). Another potential candidate in this region is an expressed sequence with similarity to the phosphatidyl inositol-3-kinase beta catalytic subunit. Phosphatidyl inositol-3-kinase is a key enzyme in insulin signal transduction.

The region of interest on chromosome 4 flanked by $D 4 S 2629$ and $D 4 S 3248$ with evidence of linkage to fasting plasma insulin concentration maps to $4 \mathrm{p} 15-\mathrm{q} 12$ and contains the gene encoding the vitamin D binding-protein (also known as groupspecific component). Polymorphisms in the vitamin D binding-protein are associated with fasting insulin concentrations in the Dogrib Indians (31) and, in elderly Dutch men, low vitamin D levels are associated with glucose intolerance and hyperinsulinemic responses during an OGTT (32).

There are no obvious candidate genes in the region on chromosome 8 with evidence of linkage to measures of insulin secretion (flanked by D8S1132-D8S592 mapping to 8p22-23). In contrast, the region on chromosome 9 with evidence of linkage to 2-h OGTT insulin concentration (markers D9S910 and D9S938 mapping to 9q21-22) contains several genes including those encoding hepatic fructose-1,6 bisphosphatase and aldolase B. Hepatic fructose-1,6 bisphosphatase, a rate-limiting enzyme in gluconeogenesis, has been investigated as a candidate gene, but two highly informative flanking markers showed no evidence of linkage to type 2 diabetes in either Caucasian or African-American families (33). Mutations in aldolase B are a cause of hereditary fructose intolerance, but have not been implicated in type 2 diabetes.

The region on chromosome 11 flanked by D11S1975 and D11S2000 (11q13) with evidence of linkage to the 2-h OGTT insulin concentration is a broad $(\sim 30 \mathrm{~cm})$ area containing many genes encoding diverse proteins. The gene for uncoupling protein-2, which is linked to a quantitative trait locus for insulin concentrations in mice, has recently been mapped to this region (34) as has the recently described uncoupling protein-3 (35). Other potential candidates in this region include galanin $(G A L N)$, a neuropeptide that inhibits insulin secretion and influences feeding behavior, phospholipase C-beta-3 (PLCB3), protein tyrosine kinase $1(M L K 3)$, the catalytic alpha subunit of protein phosphatase type 1 (PPP1CA), the PTP 


\begin{tabular}{|c|c|c|c|c|c|c|c|c|}
\hline & \multirow[b]{2}{*}{ Chromosome } & \multirow[b]{2}{*}{ Marker name } & \multirow[b]{2}{*}{ Single marker LOD } & \multirow[b]{2}{*}{$\mathrm{cM}$} & \multicolumn{4}{|c|}{ Multipoint LOD } \\
\hline & & & & & MAPMAKER/SIBS & $\mathrm{cM}$ & Variance components & $\mathrm{cM}$ \\
\hline \multicolumn{9}{|l|}{ Low dose M } \\
\hline & 2 & D2S1353 & 1.04 & 155.9 & 0.80 & 157 & 1.23 & 156 \\
\hline & 3 & D3S1764 & 2.20 & 149.9 & 2.48 & 150 & 1.13 & 150 \\
\hline & 9 & D9S168 & 1.77 & 10.0 & 1.44 & 10 & 0.99 & 10 \\
\hline & 10 & D10S579 & 0.54 & 115.4 & 1.54 & 115 & 1.45 & 116 \\
\hline & 10 & D10S2322 & 1.47 & 158.1 & 1.55 & 175 & 0.08 & 158 \\
\hline & 10 & D10S169 & 1.78 & 181.3 & 1.37 & 181 & 0.03 & 181 \\
\hline \multicolumn{9}{|l|}{ High dose M } \\
\hline & 1 & D1S1660 & 1.83 & 201.2 & 0.69 & 201 & 0.51 & 201 \\
\hline & 3 & D3S1050 & 1.57 & 7.8 & 0.69 & 8 & 0.70 & 7 \\
\hline & 3 & D3S1764 & 1.50 & 149.9 & 0.17 & 150 & 0.55 & 150 \\
\hline & 4 & D4S3255 & 2.63 & 70.1 & 0.42 & 71 & 0.55 & 74 \\
\hline & 5 & D5S815 & 0.70 & 109.9 & 0.83 & 109 & 1.73 & 110 \\
\hline & 12 & D12S1297 & 1.44 & 89.0 & 2.05 & 87 & 1.20 & 85 \\
\hline & 22 & $\mathrm{D} 22 \mathrm{~S} 420$ & 1.40 & 0 & 1.90 & 0 & 2.12 & 0 \\
\hline
\end{tabular}

All variables were adjusted for age, sex, percent fat and waist/thigh ratio.

receptor type $\mathrm{C}$ subunit associated protein $(P T P R C A P)$, and muscle glycogen phosphorylase $(P Y G M)$. A putative IDDM susceptibility locus (IDDM4) is also in this region (36). The region on chromosome 12 (around D12S1297) linked to insulin action at supraphysiologic insulin concentrations $\left(\mathrm{M}_{\text {high }}\right)$ contains a potential candidate gene, $M Y F 5$, a transcription factor involved in the differentiation of skeletal muscle which was recently shown to be regulated by insulin (37).

Chromosome 22 contained two regions of potential importance. The p-terminal region (around D22S420) showed evidence of linkage to insulin action $\left(\mathrm{M}_{\text {high }}\right)$ while the q-terminal

\section{Chromosome 3}

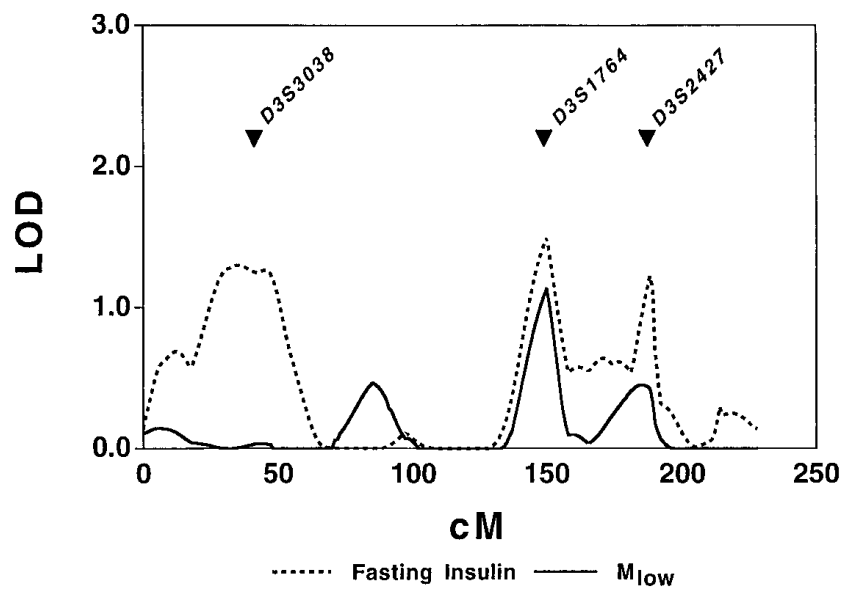

Figure 1. Variance components linkage analysis LOD scores for fasting plasma insulin concentration (dotted line) and insulin action at physiologic insulin concentrations (solid line) plotted against genetic distance (chromosome 3). region (D22S683-D22S270 mapping to 22q12-13) provided the most significant evidence of linkage to a prediabetic phenotype (fasting plasma glucose concentration) in this genomic scan. Potential candidate genes in this region include the gene encoding the somatostatin receptor 3 (SSTR3) and the structural locus for casein kinase-1 epsilon $(C S N K 1 E)$. The latter enzyme could modulate the activity of intracellular proteins involved in glucose metabolism, as do other members of this family.

In addition to these regions of interest, we specifically examined regions in which linkage to diabetes or traits predicting diabetes have been reported. There was no evidence of linkage to prediabetic phenotypes near loci tentatively linked to obesity or type 2 diabetes in Pima Indians (22). We also were un-

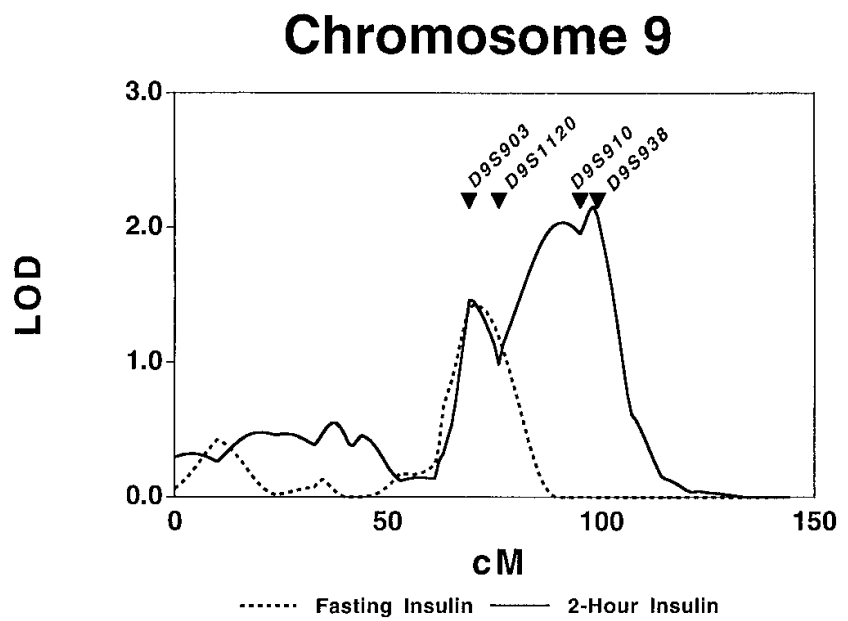

Figure 2. Variance components linkage analysis LOD scores for fasting (dotted line) and 2-h (solid line) OGTT insulin concentration plotted against genetic distance (chromosome 9 ). 


\section{Chromosome 22}

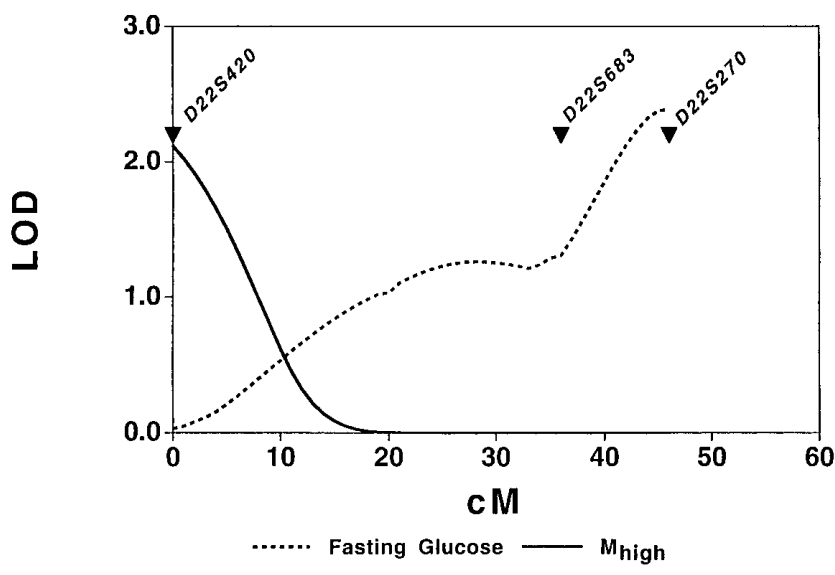

Figure 3. Variance components linkage analysis LOD scores for fasting plasma glucose concentration (dotted line) and insulin action at supraphysiologic insulin concentrations (solid line) plotted against genetic distance (chromosome 22).

able to replicate the linkage on $1 p$ to acute insulin response (38) or the linkage on $4 \mathrm{q}$ to insulin action at maximally stimulating insulin concentrations (39) previously reported in this population. The marker set used in the present genomic scan included markers flanking these regions, but not the actual markers which provided the greatest evidence of linkage in earlier studies. It is possible that the present marker set lacked sufficient resolution to detect these linkages. Alternatively, the earlier results may have been false positives.

There was no evidence that any prediabetic phenotype was linked to D2S125 on distal 2q. This locus was identified as a major susceptibility locus for type 2 diabetes (NIDDM1) in Mexican Americans from Starr County, TX (40). The locus for MODY 3 on chromosome 12 has been linked to type 2 diabetes in Finnish families characterized by impaired insulin secretion (16). We found no evidence of linkage in this region to measures of insulin secretion in the Pima Indians, nor was there any evidence of linkage at other loci implicated in MODY (TCF14 and glucokinase). We were also unable to replicate the linkages to fasting and 2-h glucose concentrations on chromosomes 6 and 11 reported in Mexican-Americans from San Antonio, TX (41). Finally, we examined regions containing putative loci for susceptibility to type 1 diabetes mellitus $(35,42$, 43). Markers linked to aspects of glucose metabolism in the present analyses that are near loci implicated in type 1 diabetes include D6S273 (near IDDM1), D8S1469, D11S1975 (near IDDM4), D14S748, and D18S64 (near IDDM6).

In summary, the results of this autosomal genomic scan suggest several regions with evidence of linkage to aspects of glucose metabolism in the Pima Indians. LOD scores in these regions were $<3.6$ (the threshold at which results would have a $5 \%$ probability of occurring in a complete genome scan) (29). Thus, these findings must be considered tentative until extended in this population or replicated in others. Nevertheless, the results of these analyses do suggest chromosomal regions in which there is an increased likelihood of finding genes contributing to type 2 diabetes among the Pima Indians.

\section{Acknowledgments}

This study would not have been possible without the ongoing cooperation and patience of the members of the Gila River Indian Community who have participated in longitudinal studies of the pathogenesis of diabetes for over $30 \mathrm{yr}$. The collection of families and DNA samples were accomplished, in large part, by the staff of the Diabetes and Arthritis Epidemiology Section including Dr. David Pettitt, Ms. Vickie Andre, Ms. Sonya Antone, and Ms. Linda Phillips. In addition, we extend our thanks to physician assistants Michael Milner and Frank Gucciardo, Ms. Carol Massengill and the nurses of the Clinical Research Unit, and Dr. Arline Salbe and the staff of the metabolic kitchen for the care of the patients in this study and the Clinical Diabetes and Nutrition Section technical staff for assisting in the analyses. The majority of the microsatellite typing was performed by the Marshfield Clinic (James Weber, David Vaske, and Monica Hamm), funded through a contract with Glaxo Wellcome. Particular thanks are also due to Derek Traughber, Gopi Gopalam, and Madhu Sethi, Glaxo Wellcome for technical assistance; Sayuko Kobes, NIDDK, Tai-He Xia, Glaxo Wellcome, and David Timberlake, Sequana Therapeutics for assistance with data analysis; Don Holt, Glaxo Wellcome for preparation of the genetic maps, Lon Cardon, Sequana Therapeutics for helpful discussions, and Michael Wagner, Quan Nguyen, Ray Grimaila, and David Yarnall, Glaxo Wellcome for selecting and genotyping markers. Information about genes located in regions showing suggestive evidence for linkage was obtained from The Genome Database (http://gdbwww.gdb.org) at Johns Hopkins University School of Medicine, Baltimore, MD, and from the Whitehead Institute/MIT Center for Genome Research, Human Genome Mapping Project (http://www-genome.wi.mit.edu/).

The Sib-Pair Linkage analyses were performed using programs of the S.A.G.E. package, which is supported by a U.S. Public Health Service Resource grant (1P41-RR-03655) from the National Center for Research Resources. Some of the work was supported by a National Institutes of Health grant (DK-47461) to W.T. Garvey and by a Collaborative Research and Development Agreement with Glaxo Wellcome, Inc. (P.H. Bennett, principal investigator).

\section{References}

1. Harris, M.I. 1995. Summary. In Diabetes in America. 2nd ed. M.I. Harris, C.C. Cowie, M.P. Stern, E.J. Boyko, G.E. Reiber, and P.H. Bennett, editors. National Institutes of Health, Bethesda, MD. 1-13.

2. Bogardus, C. 1996. Metabolic abnormalities in the development of noninsulin dependent diabetes mellitus. In Diabetes mellitus: a Fundamental and Clinical Text. D. LeRoith, S.I. Taylor, and J.M. Olejslcy, editors. LippincottRaven Publishers, Philadelphia. 459-467.

3. McCarthy, M., and G.A. Hitman. 1993. The genetic aspects of non-insulin-dependent diabetes mellitus. In The Causes of Diabetes. R.D.G. Leslie, editor. John Wiley \& Sons, London. 157-183.

4. Froguel, P., H. Zouali, N. Vionnet, G. Velho, M. Vaxillaire, F. Sun, B. Lesage, M. Stoffel, J. Takeda, P. Passa, et al. 1993. Familial hyperglycemia due to mutations in glucokinase. Definition of a subtype of diabetes mellitus. $N$. Engl. J. Med. 328:697-702.

5. Yamagata, K., N. Oda, P.J. Kaisaki, S. Menzel, H. Furata, M. Vaxillaire, L. Southam, V.V. Boriraj, X. Chen, N.J. Cox, et al. 1996. Mutations in the hepatocyte nuclear factor-1-alpha gene in maturity onset diabetes of the young (MODY3). Nature. 384:455-458.

6. Yamagata, K., H. Furata, N. Oda, P.J. Kaisaki, S. Menzel, N.J. Cox, S.S. Fajans, S. Signorini, M. Stoffel, and G. Bell. 1996. Mutations in the hepatocyte nuclear factor-4-alpha gene in maturity onset diabetes of the young (MODY1). Nature. 384:458-460.

7. Ballinger, S.W., J.M. Shoffner, E.V. Hedaya, I. Trounce, M.A. Polak, D.A., Koontz, and D.C. Wallace. 1992. Maternally transmitted diabetes and deafness associated with a 10.4-kb mitochondrial DNA deletion. Nat. Genet. 1:11-15.

8. Bogardus, C., and S. Lillioja. 1992. Pima Indians as a model to study the genetics of NIDDM. J. Cell Biochem. 48:337-343.

9. Ghosh, S. and N.J. Schork. 1996. Genetic analysis of NIDDM: the study of quantitative traits. Diabetes. 45:1-14.

10. Knowler, W.C., P.H. Bennett, R.F. Hamman, M. Miller. 1978. Diabetes incidence and prevalence in Pima Indians: a 19-fold greater incidence than in Rochester, Minnesota. Am. J. Epidemiol. 108:497-505.

11. Knowler, W.C., D.J. Pettitt, P.J. Savage, and P.H. Bennett. 1981. Diabe- 
tes incidence in Pima Indians: contributions of obesity and parental diabetes. Am. J. Epidemiol. 113:144-156.

12. Hanson, R.L, R.C. Elston, D.J. Pettitt, P.H. Bennett, and W.C. Knowler. 1995. Segregation analyses of non-insulin dependent diabetes mellitus in Pima Indians: evidence for a major-gene effect. Am. J. Human Genet. 57:160170.

13. Lillioja, S., D.M. Mott, M. Spraul, R. Ferraro, J.E. Foley, E. Ravussin, W.C. Knowler, P.H. Bennett, and C. Bogardus. 1993. Insulin resistance and insulin secretory dysfunction as precursors of non-insulin-dependent diabetes mellitus. Prospective studies of Pima Indians. N. Engl. J. Med. 329:1988-1992.

14. Sakul, H., R. Pratley, L. Cardon, E. Ravussin, D. Mott, and C. Bogardus. Familiality of physical and metabolic characteristics that predict the development of non-insulin dependent diabetes mellitus in Pima Indians. 1997. Am. J. Human Genet. 60:651-656.

15. W.H.O. (World Health Organization) Study Group on Diabetes Mellitus 1985. Diabetes Mellitus: World Health Organization Technical Report Series. Geneva: World Health Organization. 727:9-17.

16. Mahtani, M.M., E. Widen, M. Lehto, J. Thomas, M. McCarthy, J. Brayer, and B. Bryant. 1996. Mapping a gene for type 2 diabetes associated with insulin secretion defect by a genome scan in Finnish families. Nat. Genet. 14:90-94.

17. Lillioja, S., and C. Bogardus. 1988. Obesity and insulin resistance: lessons learned from the Pima Indians. Diabetes Metab. Rev. 4:517-540.

18. Schwengel, D.A., A.E. Jedlicka, E.J. Nanthakumar, J.L. Weber, and R.C. Levitt. 1994. Comparison of fluorescence-based semi-automated genotyping of multiple microsatellite loci with autoradiographic techniques. Genomics. 22:46-54.

19. Dubovsky, J., V.C. Sheffield, G.M. Duyk, and J.L. Weber. 1995. Sets of short tandem repeat polymorphisms for efficient linkage screening of the human genome. Hum. Mol. Genet. 4:449-452.

20. Ehm, M.G., and M. Wagner. 1996. Test statistic to detect errors in sibpair relationships. Am. J. Hum. Genet. 59:217a. (Abstr.)

21. Lander, E.S., and P. Green. 1987. Construction of multilocus genetic linkage maps in humans. Proc. Natl. Acad. Sci. USA. 84:2363-2367.

22. Hanson, R., and the Pima Diabetes Genes Group. 1997. Genomic scan for markers linked to type II diabetes in Pima Indians. Diabetes. 46 (Suppl. 1): 51. (Abstr.)

23. Kruglyak, L., and E.S. Lander. 1995. Complete multipoint sib-pair analysis of qualitative and quantitative traits. Am. J. Hum. Genet. 57:439-454.

24. Haseman, J.K., and R.C. Elston. 1972. The investigation of linkage between a quantitative trait and a marker locus. Behav. Genet. 2:3-19.

25. Wilson, A.F., and R. Elston. 1993. Statistical validity of the HasemanElston sib-pair test in small samples. Genet. Epidemiol. 10:593-598.

26. Chotai, J. 1984. On the LOD score method of linkage analysis. Ann. Hum. Genet. 48:359-378.

27. Amos, C.I. 1994. Robust variance-components approach for assessing genetic linkage in pedigrees. Am. J. Hum. Genet. 54:535-543.

28. Lange, K., J. Westlake, and M.A. Spence. 1976. Extensions to pedigree analysis. III. Variance components by the scoring method. Ann. Hum. Genet. 39:485-491.

29. Lander, E., and L. Kruglyak. 1995. Genetic dissection of complex traits: guideline for interpreting and reporting linkage results. Nat. Genet. 11:241-247.

30. Alonso, M.D., J. Lomako, W.M. Lomako, and W.J. Whelan. 1995. A new look at the biogenesis of glycogen. FASEB J. 12:1126-1137

31. Szathmary, E.J. 1987. The effect of GC genotype on fasting insulin levels in Dogrib Indians. Hum. Genet. 75:368-372.

32. Baynes, K.C.R., B.J. Boucher, E.J.M. Feskens, and D. Kromhout. 1997. Vitamin D, glucose tolerance and insulinemia in elderly men. Diabetologia. 40: 344-347.

33. Rothschild, C.B., B.I. Freedman, R. Hodge, P.N. Rao, M.J. Pettenati, R.A. Anderson, G. Akots, A. Qadri, B. Roh, S.S. Fajans, et al. 1995. Fructose1,6-bisphosphatase: genetic and physical mapping to human chromosome $9 \mathrm{q} 22.3$ and evaluation in non-insulin-dependent diabetes mellitus. Genomics. 29:187-194.

34. Fleury, C., M. Neverova, S. Collins, S. Raimbault, O. Champigny, C Levi-Meyrueis, F. Bouillaud, M.F. Seldin, R.S. Surwit, D. Riquier, and C.H Warden. 1997. Uncoupling protein-2: a novel gene linked to obesity and hyperinsulinemia. Nat. Genet. 15:269-276.

35. Vidal-Puig, A., G. Solanes, D. Grujic, J.S. Flier, and B.B. Lowell. 1997. UCP3 - an uncoupling protein homologue expressed preferentially and abundantly in skeletal-muscle and brown adipose-tissue. Biochem. Biophys. Res. Commun. 235:79-82.

36. Hashimoto, L., C. Habita, J.P. Beressi, M. Delepine, C. Besse, A. Cambon-Thomsen, I. Deschamps, J.I. Rotter, S. Djoulah, M.R. James, et al. 1994 Genetic mapping of a susceptibility locus for insulin-dependent diabetes on chromosome 11q. Nature. 371:161-164.

37. Thompson, D.B., M. DeGregorio, and J. Sommercorn. 1996. Insulin regulation of multiple ribonucleic acid species in human skeletal muscle in insulin-sensitive and insulin-resistant subjects. J. Clin. Endocrinol. Metab. 81:519-523.

38. Thompson, D.B., R.C. Janssen, V.M. Ossowski, M. Prochazka, W.C. Knowler, and C. Bogardus. 1995. Evidence for linkage between a region on chromosome 1p and the acute insulin response on Pima Indians. Diabetes. 44: 478-481.

39. Prochazka, M., S. Lillioja, J.F. Tait, W.C. Knowler, D.M. Mott, M Spraul, P.H. Bennett, and C. Bogardus. 1993. Linkage of chromosomal markers on $4 \mathrm{q}$ with a putative gene determining maximal insulin action in Pima Indians. Diabetes. 42:514-519.

40. Hanis, C.L., E. Boerwinkle, R. Chakraborty, D.L. Ellsworth, P. Concannon, B. Stirling, V.A. Morrison, B. Wapelhorst, R.S. Spielman, K.J. GogolinEwens, et al. 1996. A genome-wide search for human non-insulin-dependent (type 2) diabetes genes reveals a major susceptibility locus on chromosome 2. Nat. Genet. 13:161-166.

41. Stern, M.P., R. Duggirala, D.B. Mitchell, L.J. Reinhart, S. Shivakumar, P.A. Shipman, O.C. Uresandi, E. Benavides, J. Blangero, and P. O'Connell. 1996. Evidence for linkage of regions on chromosomes 6 and 11 to plasma glucose concentrations in Mexican Americans. Genome Res. 6:724-734.

42. Davies, J.L., Y. Kawaguchi, S.T. Bennet, J.B. Copeman, H.J. Cordell, L.E. Pritchard, P.W. Reed, S.C. Gough, S.C. Jenkins, S.M. Palmer, et al. 1994 A genome-wide search for human type 1 diabetes susceptibility genes. Nature. 371:130-136.

43. Elbein, S.C., M.D. Hoffman, R.A. Mayorga, K.L. Barrett, M. Leppert, and S. Hasstedt. 1997. Do non-insulin-dependent diabetes mellitus (NIDDM) and insulin-dependent diabetes mellitus (IDDM) share genetic susceptibility loci? An analysis of putative IDDM susceptibility regions in familial NIDDM. Metab. Clin. Exp. 46:48-52. 